\title{
LÍMITES AL DERECHO DE AUTOR EN FAVOR \\ DE LAS BIBLIOTECAS DIGITALES COMO PRESUPUESTO DEL DERECHO FUNDAMENTAL
}

\author{
DE ACCESO A LA CULTURA
}

\author{
ANA MARÍA PEREDA MIRABAL*
}

\section{INTRODUCCIÓN}

El derecho de acceso a la cultura, como un derecho fundamental que garantiza al individuo el acceso a la producción científica, literaria y artística de la sociedad, ha sido aceptado y consagrado desde el punto de vista doctrinal y legislativo tanto a nivel internacional como nacional; sin embargo, no estamos ante un tema zanjado ni donde existen posturas unitarias, develando su naturaleza de fundamental a partir de los criterios teóricos y jurisprudenciales que siguen unos y otros autores para determinar cuándo un derecho adquiere el rango de fundamental; lo anterior, sin desconocer los debates actuales sobre el llamado test de fundamentabilidad y las polémicas sobre la existencia o no de diferencias reales entre las categorías derechos fundamentales, derechos humanos y derechos constitucionales.

Sin ser objeto del presente trabajo la teorización respecto a lo enunciado anteriormente y partiendo de entender el derecho de acceso a la cultura como un derecho fundamental, cabe decir que a nivel internacional diversos son los instrumentos que consagran este derecho, no obstante lo cual aún no cuenta con la debida protección e implementación en cada país. En no pocas ocasiones corresponde a otros derechos, como el de autor, brindar esta protección, mediante la implementación de un sistema de límites y excepciones a favor de bibliotecas, incluidas las digitales, que se erija como presupuesto para la existencia misma del derecho de acceso a la cultura.

* Licenciada en Derecho. Especialista en Organización y Gestión del Estado. Máster en Derecho Civil. Profesora auxiliar de Derecho de Autor y Derecho Civil, Parte General en la Universidad de Pinar del Río "Hermanos Saíz Montes de Oca". Notaria con protocolo docente en la provincia de Pinar del Río, Cuba. La Habana (Cuba). Correo electrónico: anamariapereda5@gmail.com Fecha de recepción: 5 de abril de 2018. Fecha de aceptación: 16 de mayo de 2018. Para citar el artículo: Pereda Mirabal, A. M. "Límites al derecho de autor en favor de las bibliotecas digitales como presupuesto del derecho fundamental de acceso a la cultura", Revista La Propiedad Inmaterial n. ${ }^{\circ} 25$, Universidad Externado de Colombia, enero-junio 2018, pp. 123-140. Dor: https://doi. org/10.18601/16571959.n25.06 
La tesis anterior encuentra respaldo doctrinal en las funciones y finalidad del derecho de autor, reconociendo que dentro de su función no solo está la de salvaguardar los intereses morales y patrimoniales del autor, sino también la satisfacción de un interés público, pues promueve la actividad creadora en beneficio de la humanidad y le aporta toda la creación intelectual que se agrupa bajo del término cultura.

Ahora bien, en la configuración de este derecho de acceso a la cultura como derecho fundamental y en su consagración como tal en los ordenamientos jurídicos, los poderes políticos juegan un rol protagónico, especialmente el Estado, por corresponderle, a través de instituciones públicas, como las bibliotecas, garantizar que los ciudadanos puedan acceder a los bienes culturales, la información y el conocimiento; lo que inevitablemente traduce la responsabilidad de los gobiernos en el proceso de creación e implementación de mecanismos que permitan a cada persona tener un contacto real con la producción cultural de los pueblos, naciones y en general del mundo.

\section{DERECHO DE ACCESO A LA CULTURA: DEFINICIÓN CONCEPTUAL Y APROXIMACIÓN A SUS FUENTES ACTUALES}

La Declaración Universal de Derechos Humanos de 1948 en su artículo 27 consagra dos principios, a saber: 1) toda persona tiene el derecho de participar libremente en la vida cultural de la comunidad, a disfrutar de las artes y compartir el avance científico y sus beneficios, y 2) toda persona tiene derecho a la protección de sus intereses morales y materiales que resulten de cualquier producción científica, literaria o artística de la cual ella sea su autora; de lo que se colige que el primero destaca en un sentido amplio el interés público y en un sentido estricto un derecho humano de acceso a la cultura, que tendrá un beneficio individual para su titular, mientras que el segundo resalta el derecho de propiedad intelectual que tendrán los autores sobre sus creaciones.

El artículo en cuestión muestra dos vertientes si de participación en el abanico cultural se trata: una faz activa, que se identifica con el derecho dimanante del actuar creador de las personas, y una faz pasiva, que se corresponde en sentido general con los consumidores de ese producto final de la creación intelectual. En esta segunda acepción es donde cobra vida el llamado derecho de acceso al conocimiento o la cultura, como un derecho típico de segunda generación que irradia a un número indefinido de individuos y que lógicamente demanda de prestaciones vinculadas a los servicios públicos a gran escala, como pueden ser: archivos, museos, bibliotecas (tradicionales y digitales) $\mathrm{u}$ otras instituciones que sirvan de intermediarias entre los autores titulares del derecho sobre la obra y el público consumidor de la misma.

En sintonía con el artículo 27 inciso 1 reseñado, se agrega el artículo 15 del Pacto Internacional de Derechos Económicos, Sociales y Culturales (1966) (adoptado y abierto a la firma, ratificación y adhesión por la Asamblea General de las 
Naciones Unidas, mediante Resolución 2200 (xxI), el 16 de diciembre de 1966). El mismo determina en su inciso 1 ( $\mathrm{a}-\mathrm{b})$ : "Los Estados Partes en el presente pacto reconocen el derecho de toda persona a: a. participar en la vida cultural; b. gozar de los beneficios del progreso científico y de sus aplicaciones...”. Además, su inciso 2 estipula: "Entre las medidas que los Estados Partes deberán adoptar para asegurar el pleno ejercicio de este derecho, figurarán las necesarias para la conservación, el desarrollo y la difusión de la ciencia y la cultura". De manera que se reafirma lo dicho anteriormente en cuanto al derecho de "acceso" (con la participación pasiva) de todo individuo a la cultura, y la obligación del Estado de garantizar el mismo. Cabe agregar que "los derechos económicos, sociales y culturales son derechos de participación, es decir, derechos que tienen como principal objetivo asegurar la participación de las personas, así como de los grupos o colectividades en que se integran, en la vida política, económica, social y cultural o, en fin, en cualquier aspecto o faceta de la actividad humana"1.

Por otra parte, la Convención sobre la Protección y Promoción de la Diversidad de las Expresiones Culturales, adoptada en la 33. a reunión de la Unicef, celebrada en París el 21 de octubre de 2005, que entró en vigor el 18 de marzo de 2007, en su artículo 29 consagra que el derecho de acceso a la cultura debe ser equitativo, en aras de lograr un acceso libre, que llegue a todos y que sea igual para cada individuo con respecto a las obras que conforman el acervo cultural de cada nación, incluyendo el conocimiento de obras internacionales.

A su turno, el artículo 2 inciso 7 de la aludida Convención avala el "principio de acceso equitativo", entendiendo que "[e]l acceso equitativo a una gama rica y diversificada de expresiones culturales procedentes de todas las partes del mundo y el acceso de las culturas a los medios de expresión y difusión son elementos importantes para valorizar la diversidad cultural y propiciar el entendimiento mutuo". A fin de garantizar lo preceptuado, se atenderá no solo a la protección de estas expresiones culturales en el orden nacional (art. 6) sino también a su promoción (nacional-internacional). En este último caso, el artículo 7 dispone que las partes de dicha Convención deberán procurar crear en su territorio un entorno que "incite" a las personas y grupos a "(a) crear, producir, difundir y distribuir sus propias expresiones culturales, y tener acceso a ellas, prestando la debida atención a las circunstancias y necesidades especiales de las mujeres y de distintos grupos sociales, comprendidas las personas pertenecientes a minorías y los pueblos autóctonos", y, además, "(b) tener acceso a las diversas expresiones culturales procedentes de su territorio y de los demás países del mundo”2.

1 Velázquez, A. C. "Declaración Universal de los Derechos Humanos: artículo 27, derecho a la cultura", en La Declaración Universal de los Derechos Humanos en su 50 aniversario, Barcelona, Bosch, 1998, p. 255.

2 Caballero, E. A. El derecho de autor frente al derecho de acceso a la cultura: propuestas de flexibilización al régimen actual, tesis para optar al título de abogado, Universidad Abierta Interamericana, Argentina, 2013, p. 55. 
En la Xvi Cumbre de Jefes de Estado y de Gobierno Iberoamericanos, celebrada en Montevideo en noviembre de 2006, se aprueba por mayoría la Carta Cultural Iberoamericana y, según Custodio Castañeyra, es este texto internacional el que se aventura a dar una definición de derechos culturales, siendo esta la primera aproximación o referencia conceptual, al menos desde el punto de vista normativo, a lo que entenderemos por derecho de acceso a la cultura. El mentado texto reza:

\begin{abstract}
Derechos de carácter fundamental según los principios de universalidad, indivisibilidad $e$ interdependencia. Su ejercicio se desarrolla en el marco del carácter integral de los derechos humanos, de forma tal, que ese mismo ejercicio permite y facilita, a todos los individuos y grupos, la realización de sus capacidades creativas, así como el acceso, la participación y el disfrute de la cultura. Estos derechos son la base de la plena ciudadanía y hacen de los individuos, en el colectivo social, los protagonistas del quehacer en el campo de la cultura ${ }^{3}$.
\end{abstract}

Resulta oportuno, como señala de nuevo Custodio Castañeyra, tener presente lo acontecido al respecto en la ONU, por constituir una serie de hitos significativos para la concreción de estos también llamados derechos culturales, a saber: 1) la aprobación de la Observación General n. ${ }^{\circ} 21$ sobre el derecho a participar en la vida cultural, en Ginebra, el 19 de noviembre de 2009; 2) la creación ese mismo año del mandato para la figura de "experto independiente" en el ámbito de los derechos culturales; y 3) el Protocolo Facultativo del Pacto Internacional de Derechos Económicos, Sociales y Culturales (PIDESC), instrumento por el cual estos derechos son justificables, ya que facultan a cualquiera a denunciar una violación de sus derechos culturales ante el Comité Económico y Social de las Naciones Unidas; calificado este protocolo de gran avance por los internacionalistas ${ }^{4}$.

El derecho de acceso a la cultura, como se ha expuesto hasta aquí, se consagra como un derecho de segunda generación y se agrupa dentro del conjunto de los derechos económicos, sociales y culturales (DESC). Su construcción dogmática es en extremo difícil, pues no es algo que ocupe solo al derecho sino que tiene fuertes componentes históricos y de reivindicaciones sociales. Lo anterior nos hace transitar por terrenos poco nobles y en extremo sensibles, por ser un derecho humano que pertenece a cada persona pero que igualmente necesita una clarificación conceptual y una regulación seria en aras de no vulnerar otros derechos igualmente reconocidos y consagrados como fundamentales.

Es por lo demás una responsabilidad de los poderes públicos el consagrar, regular y viabilizar el ejercicio de estos derechos a través de sus instituciones, y le

3 Custodio Castañeyra, T. "Aproximación dogmática a los derechos culturales (E1 derecho a la cultura como derecho fundamental)", Cuadernos de Derecho de la Cultura n. ${ }^{\circ}$ 5, Instituto Interuniversitario para la Comunicación Cultural, UC3M-Uned C/Madrid 126, 28903, Getafe, Madrid, 2014, p. 21, disponible en: http://hdl.handle.net/10016/18206 [consultado el 14 de septiembre de 2017].

4 Custodio Castañeyra, ob. cit., p. in. 
corresponde a la jurisprudencia sentar pautas para garantizar el ejercicio efectivo del derecho de acceso a la cultura, pues sin lugar a dudas estamos en momentos que son cruciales para estos derechos de segunda generación, dados los cambios vertiginosos que se están produciendo a escala global, especialmente en el entorno digital.

Doctrinalmente existen varios argumentos a favor o en contra de considerar al Derecho de Acceso a la Cultura como un derecho fundamental; estudios al respecto han concluido que su asunción o no como tal se hará depender de las concepciones de lo que es el derecho a la cultura y del estatus jurídico que se le otorgue; estatus que depende, además, de los presupuestos ideológicos de los que ostentan el poder legislativo y su voluntad o de su poder político en un momento determinado 5 .

Al no ser objetivo del presente trabajo desentrañar la naturaleza jurídica del derecho de acceso a la cultura y asumiendo el criterio mayoritario, que por lo demás compartimos, de que es un derecho fundamental, consideramos pertinente asumir la definición que ofrece Caballero:

"Derecho de acceso a la cultura" es la facultad de todo individuo a participar en forma pasiva de la diversidad cultural humana, a través del acceso efectivo a obras culturales que lo componen en sus tres órdenes genéricos: ciencia, literatura y arte, y cuyo deber de prestación recae en los poderes públicos (nación, provincia, municipio) a través de servicios esenciales para su satisfacción (bibliotecas, archivos, escuelas, universidades, entre otros), en conjunción de un orden positivo que facilite su ejercicio ${ }^{6}$.

\section{LA IMPRONTA DE LA REGULACIÓN DE LOS DERECHOS DE AUTOR \\ EN EL ACCESO A LA CULTURA}

El objeto de protección del derecho de autor lo constituye sin lugar a dudas la obra; sin embargo, ¿qué debemos entender por tal? En su sentido literal, según el diccionario, como "obra” se clasificaría en general cualquier producción del entendimiento en ciencias, letras o artes ${ }^{7}$; si se asume un significado técnico jurídico habría que ceñirse a la definición que brinda el Glosario de la Organización Mundial de la Propiedad Intelectual (ompr) de Derecho de Autor y Derechos Conexos (1980), donde se lee: "obra es toda creación intelectual original expresada en una forma reproducible" .

5 Champeil-Desplats, V. "El derecho a la cultura como derecho fundamental", Revista Electrónica Iberoamericana del Centro de Estudios de Iberoamérica, vol. 4, n. ${ }^{\circ}$ 1, 2010, pp. 114, disponible en: http://www.urjc.es/ceib [consultado el 12 de septiembre de 2017].

6 Caballero, ob. cit., p. 56.

7 Cfr. Alvero Francés, F. Cervantes. Diccionario Manual de la Lengua Española, La Habana, Editorial Pueblo y Educación, 1976, p. 547.

8 Glosario de la OMPI de Derecho de Autor y Derechos Conexos, Ginebra, 1980, voz 262 , p. 268. 
Así, se puede concluir que estaremos en presencia de una obra cuando se alude a una creación surgida del hombre, es decir, proveniente del intelecto humano, cuya forma de expresarse es original y distinta de las ya existentes dentro de su mismo género. Tales productos del ingenio pueden expresarse en la esfera artística, literaria o científica, y en todos los casos deben ser aptos para ser divulgados, otorgando en consecuencia un conjunto de facultades morales y patrimoniales sobre esas creaciones?.

Dentro de este derecho subjetivo abstractamente considerado se evidencia un conjunto de facultades que se han identificado como morales y patrimoniales, y que constituyen el contenido de este derecho. Se identifica como contenido moral del derecho de autor, por la doctrina y la práctica jurídica, al conjunto de facultades de carácter personalísimo mediante las cuales se protege a la persona del autor a través de su obra y la especial relación entre ambos; constituyen, por ende, la expresión de la personalidad del creador, sin que ello implique una compensación económica.

No obstante, estas facultades personales se ven complementadas por las llamadas facultades patrimoniales, que se caracterizan por ser exclusivas, transferibles, renunciables y de una duración limitada, reportando su ejercicio beneficios económicos al autor, pues traen aparejada una remuneración.

Dentro de las facultades de carácter patrimonial cabe distinguir, a su vez, entre las de carácter exclusivo, que son aquellas que atribuyen a su titular la facultad de autorizar o prohibir la utilización de la obra o prestación, y las de simple remuneración, en virtud de las cuales, si bien se priva a los titulares de la posibilidad de autorizar el acto de explotación, se les reconoce una participación económica derivada del mismo, estando determinado dicho contenido económico por la ley (copia privada, derecho de participación) o bien fijado por los titulares de los derechos en negociación con el utilizador ${ }^{10}$.

El objeto de protección del derecho de autor es la obra como acto de creación; por ende, se ha sostenido que su finalidad en sentido estricto es la de preservar la realización personal y económica del autor. Sin desvirtuar la tesis anterior, hay que tener en cuenta el contenido social de este derecho, y por ello habrá que reconocer que, además de lo antes expuesto, dentro de su fin debe incluirse el de proteger la difusión del conocimiento y la promoción de la creación.

La necesidad de armonizar intereses privados y públicos es una constante para las legislaciones autorales, razón que justifica la implementación de excepciones

9 Con base en la teoría monista, el derecho de autor es considerado como un único derecho subjetivo que surge con el acto de creación, integrado por diferentes facultades, unas personales o morales y otras patrimoniales o económicas; no obstante, dada la primacía de la doctrina dualista durante largo tiempo, estas facultades a veces han sido tomadas en la doctrina y las legislaciones como si se tratara de dos derechos subjetivos diferentes. Es de aclarar que en el presente trabajo se empelarán indistintamente los términos derechos y facultades, aunque no son técnicamente coincidentes.

10 "Tercer Seminario Regional sobre Propiedad Intelectual para Jueces y Fiscales de América Latina”, OMPI/PI/Ju/LAC/04/18, disponible en: http://www.wipo.int/edocs/mdocs/ mdocs/es/ompi_pi_ju_lac_04/ompi_pi_ju_lac_04_1 8.doc [consultado el 25 de mayo de 2018]. 
y limitaciones sobre el alcance y el ejercicio de los derechos objeto de protección. Tienen entonces las normas de derecho de autor el reto de armonizar los intereses de los creadores con los de usuarios y proveedores de servicios, en aras de salvaguardar derechos como el de acceso a la cultura, al conocimiento y a la información.

Para satisfacer esta exigencia, que es esencia y no potencia, las normas que regulan los derechos de los autores han establecido un conjunto de situaciones en las cuales las obras pueden ser utilizadas o disfrutadas sin que ello implique la autorización del titular del derecho ni la remuneración, y que en definitiva resguardan un interés específico que a juicio del legislador es importante proteger, siendo lo que se conoce técnicamente como excepciones y limitaciones al derecho de autor.

Como se viene exponiendo, el ejercicio de las facultades autorales que en su conjunto y de forma unitaria conceden a su titular un derecho exclusivo, encuentra un límite al amparo de un interés social, pero cuidando en todo momento que la afectación al autor sea mínima o inexistente ${ }^{11}$.

Desde sus surgimiento, el derecho de autor ha tratado de armonizar los derechos del creador titular de la obra o sus causahabientes, así como el interés general de la sociedad de acceder a las creaciones del intelecto, porque en definitiva son intereses perfectamente compatibles que no tienen que contraponerse siempre que se desarrollen sobre la base de la competencia leal y el acceso a un disfrute equitativo de la creación; entendiéndose por tal la posibilidad de coexistencia pacífica de autores y utilizadores de la obra, donde exista un equilibro entre la explotación de la obra y el uso y disfrute del público que la recibe.

Aun cuando la realidad social y jurídica intente armonizar las posiciones anteriores, es evidente que el acceso a las obras por parte de los usuarios históricamente ha creado situaciones conflictuales, pues en no pocos casos este proceso de difusión y acceso origina tensiones entre creadores y público consumidor.

Esta realidad ha hecho que muchos se pregunten cómo es que influyen las leyes autorales para que exista un ejercicio legítimo del derecho de acceso a la cultura. La respuesta es sencilla, sobre la base de lo que se viene aduciendo: el derecho de autor no solo se encarga de proteger los interese económicos de los creadores, sino también los personales; y si los autores se ven desprotegidos en estas esferas se produce desmotivación, lo que no solo afecta a la persona natural sino a toda la sociedad, pues se detiene la actividad creativa y se empobrece el acervo cultural; de ahí la necesidad de una adecuada regulación legal de ese interés privado del autor que se revierte en la satisfacción de un interés público.

Sin duda, un sistema de protección autoral que garantice el disfrute justo y equitativo de las facultades que posee aquel que crea una obra constituye una premisa para proporcionar a su vez un legítimo acceso a esta producción intelectual. Siempre que existan normas que regulen adecuadamente los plazos de protección, la entrada de la obra al dominio público, ya sea gratuito u oneroso, los límites

11 Excepciones de Berna no Sujetas a la Regla de los Tres Pasos, disponible en: http:// keionline.org/node/1518 [consultado el 30 de agosto de 2016]. 
al derecho subjetivo de los autores sobre el test de los tres pasos, por un lado, y, por otro, cuerpos normativos que legalicen el actuar de bibliotecas, museos y/o archivos, tanto públicos como privados, desde donde se puedan usar las obras, con fines académicos, científicos e investigativos, se estará ante un sistema idóneo para garantizar el derecho de acceso a la cultura sin lacerar ni perjudicar a los autores ni lesionar su derecho subjetivo.

Como se ha dicho, el derecho de autor no solo busca la protección personal y económica de los creadores, pues dentro de sus fines se encuentra de igual forma la satisfacción de un interés público al ser fuente generadora de cultura. Cuando las normas jurídicas que regulan los derechos de los autores logran establecer un sistema de límites y excepciones en favor de bibliotecas, especialmente las digitales, garantizan a cada persona el derecho de acceso a la cultura, al restituir a estas entidades su rol protagónico como garantes del supramentado derecho, en su faz pasiva.

\section{PAPEL DE LAS BIBLIOTECAS COMO GARANTES DEL ACCESO}

\section{A LA CULTURA: ESPECIAL REFERENCIA AL ENTORNO DIGITAL}

Sabido es que en el proceso de difusión de las obras intervienen múltiples actores y factores; sin embargo, se hace necesario hacer referencia a instituciones que desde un remoto pasado han contribuido o servido de puente entre creadores y públicos: las bibliotecas.

La biblioteca es un sistema que selecciona, adquiere, organiza, representa, almacena y distribuye información para una comunidad de usuarios, con independencia del medio que soporte dichos procesos y la interface [sic] por medio de la cual interactúe el usuario con el sistema. Actualmente suelen clasificarse según el uso que hacen de las tecnologías de la información y la comunicación para desarrollar los procesos, sin desconocer la ambigüedad en cuanto al uso de los diferentes términos; la tipología incluye desde las bibliotecas que no emplean las tecnologías de información y comunicación hasta las que realizan cada uno de sus procesos en ambiente digital. Se habla entonces de bibliotecas tradicional, electrónica, híbrida, virtual y digital ${ }^{12}$.

Como su nombre lo indica, el término biblioteca tradicional o clásica se reserva a las bibliotecas que realizan sus procesos sin el empleo, o con muy poco empleo, de las tecnologías de información y comunicación. Se distinguen por poseer los contenidos en soporte de papel y el acceso se realiza mediante referencias bibliográficas contenidas en los catálogos. Estas bibliotecas son hoy las menos, la mayoría 
emplea herramientas tecnológicas en diversos grados para ejecutar algunos o todos sus procesos ${ }^{13}$.

Ortiz Repiso y Moscoso señalan que la biblioteca electrónica hace referencia a un concepto de biblioteca todavía asociado a la noción de un espacio físico, pero desde el cual los usuarios pueden acceder a recursos impresos y digitales, si bien no de una forma integrada. Estos recursos se seleccionan, adquieren y procesan con el fin de recuperarlos por medio de sistemas informáticos, de una manera parecida a como se hace con los recursos tradicionales ${ }^{14}$.

Ramírez Céspedes sostiene que biblioteca híbrida es el término que muchos autores emplean para identificar aquella biblioteca que está en un período de transición hacia la biblioteca digital. Es decir, un estadio intermedio entre la biblioteca tradicional y la virtual, donde coexisten ambos formatos, y por lo tanto pueden existir servicios tradicionales y servicios en ambiente digital ${ }^{15}$.

Al decir de Urra ${ }^{16}$, en una biblioteca virtual es necesario que las fuentes de información estén disponibles de alguna manera y su acceso sea ubicuo, es decir, sin importar dónde residen físicamente sus usuarios ni quién se encarga específicamente de su procesamiento y almacenamiento. Predomina el concepto de biblioteca como espacio y como proceso, por lo que es un concepto que refleja el dinamismo de internet. A la luz de lo anterior, Ramírez Céspedes concluye que la biblioteca virtual ha sido definida como una colección de recursos web, o como aquella que por medio de la realidad virtual y la inteligencia artificial intenta modelar un ambiente similar al existente en una biblioteca tradicional ${ }^{17}$.

York nos recuerda que en el año 2003 la Federación de Bibliotecas Digitales dio una definición que expresa de manera clara el concepto de biblioteca digital:

Las bibliotecas digitales son organizaciones que fomentan los recursos, incluido el personal especializado, para seleccionar, estructurar, ofrecer acceso intelectual, traducir, distribuir, preservar la integridad y garantizar la permanencia de las colecciones digitales, de forma que estén disponibles para una o varias comunidades en un ambiente internacional coordinado ${ }^{18}$.

Con independencia de la clasificación que corresponda, teniendo en cuenta la forma en que prestan sus servicios, lo cierto es que las bibliotecas facilitan el acceso a la información y hacen que los usuarios puedan utilizar las obras de creación intelectual con fines disímiles. Lo expuesto reafirma la idea inicial de que son

13 Ibíd.

14 Ortiz Repiso, V. y Moscoso, P. "La biblioteca digital: inventado el futuro", info 2002, La Habana, IDICT, 2002.

15 Ramírez Céspedes, ob. cit.

16 Urra P. "Análisis del paradigma de la complejidad para reducir la perplejidad que produce el acceso a las redes", INFO-2006, La Habana, IDICT, 2006.

17 Ramírez Céspedes. "Criterios e indicadores para evaluar las bibliotecas digitales", cit.

18 York V. A. "Biblioteca digital. Recursos y proyectos", disponible en: http://www. cg.org.br/gt/gtbv/yorkatibict/tsld004.htm [consultado 30 de septiembre de 2017]. 
estas instituciones el puente entre creadores e individuos, al ser facilitadoras de la difusión de las obras, del acceso al conocimiento y la información, elementos que integran el llamado derecho a la cultura. Sin embargo, en esta relación autoresbibliotecas-público consumidor, la relación no siempre es apacible, pudiendo existir una colisión entre las normas que regulan y protegen el derecho de los creadores y aquellas que salvaguardan el derecho a la información del que son garantes las bibliotecas, conflicto dado en alguna medida por la falta de flexibilidad en las regulaciones normativas o por su no adecuación a los nuevos contextos.

En este sentido, cuando existan normas de derecho de autor que no se correspondan con la realidad social y que limiten la actuación de las bibliotecas, se producirá una afectación a la función de estas. Piénsese en los servicios que prestan a los usuarios, o en las condiciones en que se los proporcionan, cuando las normas jurídicas de protección resultan excluyentes o simplemente se carece de un sistema de limitaciones para bibliotecas, o existe una regulación que no es suficiente o es del todo inadecuada a las circunstancias socioeconómicas. Cuando se suscitan situaciones como estas se crea rápidamente una brecha entre quienes disponen de información y aquellos que tratan de acceder a ella, y a largo plazo afectará la actividad de custodia de las obras del intelecto propia de la misión de las bibliotecas.

Las afectaciones descritas no se manifiestan unilateralmente sino que, dadas las dificultades para el desarrollo de sus funciones y las situaciones de conflicto que se les originen a las bibliotecas en su actividad de facilitar el acceso a la información, se puede producir una afectación también a los autores; en efecto, estos pueden verse lesionados por conductas violatorias (piratería, falsificación, plagio o cualquier otra que lesione sus facultades morales y/o patrimoniales) por parte de usuarios que carecen de medios lícitos para acceder a las obras; situación que se evita con la implementación de excepciones sobre la regla de los tres pasos, a la actividad de las bibliotecas, incluidas las digitales.

Es racional entender entonces que las bibliotecas pueden contribuir a que las normas autorales no se infrinjan, partiendo del hecho cierto de que han sido las instituciones que han facilitado a los usuarios el acceso a la información y han velado por que este proceso se realice sin perjuicio a los intereses de los autores y titulares del derecho.

En la actualidad aparece una variable que replantea la relación bibliotecasautores-derecho de acceso a la cultura-ejercicio legítimo de las facultades autorales, a saber: la digitalización del conocimiento. Las tecnologías han dado lugar a una transpolación vertiginosa del mundo analógico al digital, ofreciendo la red a los ciudadanos del mundo acceso al conocimiento colectivo de toda la humanidad.

Es común que, con apoyo en las nuevas tecnologías, las bibliotecas más grandes del mundo estén digitalizando sus colecciones, e incluso que existan, como se explicó, bibliotecas virtuales, digitales, electrónicas o híbridas.

Proyectos como "Gutenberg" y "Wikis" han puesto a disposición de las personas un número importante de obras artísticas, literarias, científicas, etc. que pueden ser 
consultadas en la red. Las tecnologías de la informática y las comunicaciones cada vez más permiten el acceso a la información, facilitando el proceso de resiliencia del conocimiento. Hoy en día es una realidad la digitalización de la producción intelectual de la humanidad, accesible vía internet o mediante plataformas globales desde casi todos los puntos del orbe.

Las consecuencias negativas de este proceso, que tiene lugar en la sociedad del conocimiento, han repercutido tanto en las bibliotecas como en los autores. La era digital, caracterizada por la universalidad, la deslocalización, la virtualidad y la desmaterialización, ha hecho necesario replantear los límites al derecho de autor.

Las normas consagradas en el Convenio de Berna sobre objeto de protección y autoría encuentran plena vigencia y son de aplicación directa tanto en el mundo analógico como el digital. Siguiendo los postulados de la Convención, no se hace necesario establecer requisitos ni formalidades para determinar la existencia de una obra y su protección por la normas autorales.

Cosa distinta es que el derecho de autor necesite adaptarse a las nuevas demandas, sin abandonar sus principios rectores básicos. En su momento el desarrollo industrial, la aparición de la imprenta, el fonógrafo y el cinematógrafo produjeron cambios radicales, pues la cultura y el modo de acceder al conocimiento adquirieron nuevas dimensiones. Actualmente las Tics producen nuevas y profundas transformaciones con trascendencia jurídica, y el beneficio que ofrecen en ningún caso puede soslayar las facultades de los creadores, pues desproteger la actividad de creación intelectual comportaría a largo o mediano plazo un obstáculo para la evolución de la sociedad.

Los desafíos a los que se enfrenta el derecho de autor en el siglo XxI, marcados esencialmente por las nuevas formas de acceso a las creaciones intelectuales protegidas y por la elevada posibilidad de que se produzcan violaciones a los derechos de los autores, evidencian la necesidad de adaptar los mecanismos de protección, de redefinir conceptos, de desconstruir algunos de ellos para reconstruirlos desde una nueva perspectiva; pero nunca de destruir el derecho de autor.

No se debe olvidar que, lejos de entorpecer el desarrollo, este derecho es fuente generadora del mismo, al ser propulsor de conocimiento, cultura y libertad de expresión. Se debe recordar asimismo que las bibliotecas digitales, al igual que sus antecesoras (las clásicas), se erigen como garantes del equilibrio entre los intereses del público y los de los autores, armonía que debe estar garantizada por un adecuado sistema de límites al derecho de autor estructurado sobre la regla de los tres pasos.

En tal sentido cobran protagonismo las llamadas bibliotecas on line, puesto que estas contribuyen al acceso a la cultura y son más acordes con la tecnología de la sociedad contemporánea. Por ello, "el reto es actualizar la legislación y asegurar que el balance entre creadores y lectores se mantenga en la era digital"19.

19 Pelaya, L. y Sanllorenti, A. "El acceso a la información en el contexto de la Ley 11.723: una mirada desde las bibliotecas”, en ACBJ. Revista de la Asociación Civil de Bibliotecarios Jurídicos, n.o 4, Abeledo Perrot, 2009, p. 19. 
Cuando se rompe esta armonía surgen inevitablemente las tensiones. Es por tanto una premisa en la realidad de hoy lograr una armonía entre el acceso a la cultura o los bienes culturales, como derecho humano fundamental, y la protección a los creadores, entendiendo el derecho de propiedad intelectual como un derecho fundamental también, y además reconociendo, como afirma Espín Alba, que la convivencia del derecho de autor con otros derechos subjetivos es una historia de ponderación, que se refleja intrínsecamente en los límites y excepciones, máxime si recordamos que tales limitaciones se han mantenido casi inmutables ante los cambios tecnológicos de las últimas décadas y la ampliación de la normas de protección, lo que en la era digital origina un problema ${ }^{20}$.

Existe asimismo la necesidad de alentar a las bibliotecas a que conozcan de forma estructurada el Derecho de Autor ante el desarrollo de las tecnologías de la información y las comunicaciones (TICS), donde virtualmente la biblioteca tiene millones de usuarios y puede incrementar los contenidos y servicios de sus colecciones a escala mundial, pero a la vez debe respeto del derecho de autor, de lo que se colige que es indispensable aprovechar el desarrollo tecnológico de forma responsable actuando dentro de los márgenes legales, lo que se traduce en una actuación acorde a las excepciones y limitaciones impuestas al derecho de autor, con estricto apego a la regla de los tres pasos, sin perder de vista la flexibilidad y contemporización de dichas limitaciones a la realidad actual que trasciende la esfera analógica para insertarse cada vez más en la digital ${ }^{21}$.

A los razonamientos anteriores hay que añadir el rol de los actores y factores económicos; en este sentido, Fink agrega un dato significativo al plantear:

... es muy posible que los efectos en los precios frente a una mayor observancia de los derechos de P.I. sean limitados si la distribución de los ingresos es tal que sólo unos pocos consumidores puedan permitirse pasarse de productos infractores de los derechos de P.I. a los productos legítimos [...] [E]s el crecimiento económico sostenido lo que producirá reducciones sustanciales de los niveles de piratería en los países menos adelantados 22 .

En este caso media una distinción importante respecto a las bibliotecas, y es que, pese a las funciones de interés público que estas desempeñan, no debe mediar fin de lucro en su actividad para que sean sujeto de la excepción. Por otra parte, es interesante notar que la reproducción de la obra que realice la biblioteca para el

20 Espín Alba, I. (coord). Propiedad intelectual en el siglo XXI: nuevos continentes y su incidencia en el derecho de autor, Madrid, Reus, 2014, p. 93.

21 Cfr. Pabón Cadavid, J. "Medidas tecnológicas de protección en el Tratado de Libre Comercio con los Estados Unidos de Norteamérica”, Revista La Propiedad Inmaterial, Universidad Externado de Colombia, n.o 10-11, 2006-2007, pp. 93-115.

22 Fink, C. "La observancia de los derechos de propiedad intelectual desde una perspectiva económica”, омpI-Comité asesor sobre Observancia, 5.a sesión, Ginebra, 4 de noviembre de 2009. 
usuario no tiene por límite porcentaje alguno (como es común que suceda en los convenios que se celebran entre ciertas sociedades de autores y las bibliotecas), por el contrario, el límite de la extensión de la reproducción estará dado por el grado de justificación que brinde el usuario y la necesidad del caso, quedando esencialmente a discreción del bibliotecario ${ }^{23}$.

La excepción en beneficio de las bibliotecas en la Ley Tipo de Túnez de 1976, sobre Derecho de Autor para los Países en Vías de Desarrollo, confeccionada por la secretaría de la Unesco y la Oficina Internacional de la ompi (Ley Tipo), es sencilla si se le compara con las disposiciones detalladas de muchos países, por lo que en ejercicio de tal excepción aquellas podrán:

... reproducir por un procedimiento fotográfico u otro análogo una obra literaria, artística o científica, ya lícitamente accesible al público [...] con la condición de que dicha reproducción y el número de ejemplares se limiten a las necesidades de sus actividades y siempre que esa reproducción no afecte a la explotación normal de la obra ni cause un perjuicio injustificado a los intereses legítimos del autor ${ }^{24}$.

La situación que tiene lugar a escala internacional se refleja de igual forma en Cuba. Al tener una ley bastante obsoleta que difiere de sus homólogas, la situación adquiere connotaciones especiales; y aun cuando registra un sistema de excepciones que incluyen las limitaciones en favor de las bibliotecas, lo hace de manera insuficiente para el entorno digital. Además, en momentos en que el país vive cambios socioeconómicos importantes y se habla de un resurgir de la TICs, se hace evidente que un divorcio entre el discurso, la realidad y la normativa, especialmente en sede de derecho de autor, lejos de contribuir al fomento económico, lo dificultaría, con las consecuentes afectaciones a los creadores en el plano particular.

\section{LÍMITES AL DERECHO DE AUTOR EN FAVOR DE BIBLIOTECAS: EN BUSCA DEL EQUILIBRIO ENTRE PROTECCIÓN AUTORAL Y DERECHO DE ACCESO A LA CULTURA}

Sin desproteger a los autores, compartimos la tesis de que un sistema de derecho de autor caracterizado por una regulación rígida es en sí vulnerable, lo que a largo o mediano plazo afecta a un sector considerable de la sociedad en su derecho fundamental de acceder a los bienes culturales y a la cultura en sentido general.

Para satisfacer esta necesidad, las normas que regulan los derechos de los autores han establecido un conjunto de situaciones en las cuales las obras pueden ser utili-

23 Caballero, ob. cit., p. 110.

24 Crews, K. "Estudio sobre las limitaciones y excepciones al derecho de autor en beneficio de bibliotecas y archivos”, омpi, Ginebra, 2008, p. 27, disponible en: http:// www.wipo.int/edocs/mdocs/copyright/es/sccr_17/sccr_17_2.pdf [consultado el 30 de septiembre de 2017 . 
zadas o disfrutadas sin que ello implique la autorización del titular del derecho ni la remuneración, y que en definitiva resguardan un interés específico que a juicio del legislador es importante proteger. Se trata de lo que se conoce técnicamente como excepciones y limitaciones al derecho de autor.

De acuerdo con Pabón Cadavid, las razones para la existencia de estas excepciones son las siguientes ${ }^{25}$ :

- Función social de la propiedad (excepción de uso privado en el ámbito doméstico).

- Proteger la educación (excepción de comunicación pública para fines de enseñanza).

- Buscar la difusión de la cultura (excepción de reproducción para enseñanza).

- Lograr la eficacia de la ley (excepción para organismos de radiodifusión).

- Lograr mayor participación ciudadana en la vida democrática (reproducción de leyes).

- Buscar que los derechos de autor no sean un obstáculo para las nuevas creaciones (derecho de cita).

- No obstaculizar actividades ni investigaciones judiciales (reproducción para actuaciones judiciales).

- Conservar y proteger el patrimonio cultural (excepción para bibliotecas).

Amén de la anterior relación, que es solo enunciativa, hay que destacar que los criterios para establecer las excepciones y limitaciones se apoyan o desarrollan sobre el test o regla de los tres pasos, es decir, deben observar tres requisitos que justifican su aplicación: 1. Que sea un caso especial y específico, 2. Que con su aplicación no se atente contra la normal explotación de la obra y 3. Que con la excepción no se cause un perjuicio injustificado a los intereses legítimos del titular o titulares del derecho de autor.

La regla de los tres pasos intenta establecer una restricción a los diferentes tipos de usos justos que pueden ser permitidos en las normas internas de cada Estado. Esta prueba se contempla de forma primigenia en la revisión del Convenio de Berna en 1967, artículo 9 apartado dos, donde se dispuso: "Se reserva a las legislaciones de los países de la Unión la facultad de permitir la reproducción de dichas obras en determinados casos especiales, con tal que esa reproducción no atente a la explotación normal de la obra ni cause un perjuicio injustificado a los intereses legítimos del autor". Según el artículo 13 de los ADpic, aplican las excepciones y limitaciones a cualquiera de los "derechos exclusivos" asociados con derechos de autor.

La regulación en las convenciones y acuerdos internacionales, como se aprecia, no es unánime. Mientras Berna solo aplica las excepciones y limitaciones al derecho disponible en: blogs.ujaen.es/abiertobuja/wp-content/uploads/2014/06/GuiaDerechoAutorBibliotecas.pdf [consultado el 26 de agosto de 2017]. 
de reproducción y emplea la frase "no cause un perjuicio injustificado a los intereses legítimos del autor", los ADPIC las hacen extensiva a cualquiera de las facultades que conforman el derecho de autor y, por otro lado, emplean la expresión "no cause un perjuicio injustificado a los intereses legítimos del titular del derecho". El sutil cambio de las palabras autor y titular permite, según los ADPIC, centrar la atención en los intereses económicos de terceros, que pueden ser o son en muchos casos las empresas, que han adquirido facultades autorales por transmisión de los autores creadores de las obras, alejando la atención de los creadores y sus intereses ${ }^{26}$.

Dejando a un lado todos los análisis que pudieran soportar los sistemas de límites, limitaciones y/o excepciones al derecho de autor, es una realidad que estos límites se erigen como punto medio entre los creadores y el público que en definitiva disfrutará o se beneficiará del producto cultural, siendo la herramienta idónea para lograr el justo equilibrio entre protección autoral y derecho de acceso a la cultura. Estas limitaciones no solo permiten que los que no crean se beneficien, sino que de igual forma sirven a los creadores como fuente generadora de nuevos saberes y conocimientos, haciendo posible que el derecho de autor logre su finalidad: estimular la creación intelectual, proteger la difusión del conocimiento y la promoción de la creación, aspectos que redundan en la consagración del derecho de acceso a la cultura.

\section{CONCLUSIONES}

El derecho de acceso a la cultura ha sido considerado como un derecho fundamental, que garantiza al individuo el acceso a la producción científica, literaria y artística de la sociedad, permitiéndole el uso y disfrute de aquellos bienes culturales que han sido puestos al servicio de la humanidad y que dimanan de la actividad creativa del hombre, a partir de las diversidades culturales.

En el contexto internacional son diversos los instrumentos que consagran este derecho; sin embargo, aún no cuenta con la debida protección e implementación, al menos a nivel de cada país, siendo pertinente en este sentido resaltar la responsabilidad de los poderes públicos nacionales en la prestación de este derecho a sus individuos.

A la consecución de esta debida protección coadyuvan los límites al derecho de autor a favor de las bibliotecas, incluidas las digitales, pues se erigen como presupuesto para la existencia misma del derecho de acceso a la cultura. En efecto, dentro de la finalidad del derecho de autor se encuentra, además de la salvaguarda

26 Los conceptos de autoría y titularidad no son totalmente coincidentes, pese a la estrecha relación que existe entre ellos. Para el sistema latino, autor es la persona física que crea la obra, salvo determinadas excepciones, deviniendo titular originario del derecho; mientras que para el copyright se considera autor a toda persona que crea una obra, sea física o jurídica, la que deviene titular originario. La titularidad originaria hace alusión al conjunto de derechos que se originan en cabeza de quien nace el derecho de autor, como resultado de un acto de creación intelectual. 
de intereses personales y económicos de los creadores, la satisfacción de un interés público, a saber: la promoción de la actividad creadora en beneficio de la humanidad y el aporte a la misma de toda la creación intelectual que se engloba dentro del término cultura.

En consecuencia, corresponde a cada Estado, en cuanto ente de poder público político, a través de instituciones como las bibliotecas, incluidas las digitales, garantizar el acceso a los bienes culturales y al conocimiento, lo que inevitablemente se traduce en crear e implementar garantías que permitan a cada persona tener un contacto real con el acervo cultural de su nación y del mundo, restituyendo a entidades como las bibliotecas su rol protagónico como garantes del derecho de acceso a la cultura en su faz pasiva.

Ante la necesidad creciente de salvaguardar el derecho de acceder a la producción científica, literaria y artística de la sociedad, el presente artículo sostiene la tesis de que el derecho de autor tiene ante sí el reto de redefinir sus conceptos y reconstruir sus instituciones sin abandonar sus principios rectores; ello implica adaptar sus límites y excepciones en favor de bibliotecas a la nueva era digital, de manera que, sin rígidos esquemas, se permita el disfrute de las obras que protegen, propiciando el acceso a la cultura, sin lesionar las facultades de los autores, en un justo equilibrio entre producción intelectual, protección autoral y derecho de acceso a la cultura.

\section{REFERENCIAS}

\section{DOCTRINA}

Alvero Francés, F. Cervantes. Diccionario Manual de la Lengua Española, Editorial Pueblo y Educación, La Habana, 1976.

Caballero, E. A. El derecho de autor frente al derecho de acceso a la cultura: propuestas de flexibilización al régimen actual, tesis para optar al título de abogado, Universidad Abierta Interamericana, Argentina, 2013.

Champeil-Desplats, V. "El derecho a la cultura como derecho fundamental", Revista Electrónica Iberoamericana del Centro de Estudios de Iberoamérica, vol. 4, n. ${ }^{\circ}$ 1, 2010, disponible en: http://www.urjc.es/ceib [consultado el 12 de septiembre de 2017].

Crews, K. "Estudio sobre las limitaciones y excepciones al derecho de autor en beneficio de bibliotecas y archivos", OMPI, Ginebra, 2008, disponible en: http:// www.wipo.int/edocs/mdocs/copyright/es/sccr_17/sccr_17_2.pdf [consultado 30 de septiembre de 2017].

Custodio Castañeyra, T. "Aproximación dogmática a los derechos culturales (El derecho a la cultura como derecho fundamental)", Cuadernos de Derecho de la Cultura, n. ${ }^{\circ}$ 5, Instituto Interuniversitario para la Comunicación Cultural, uC3M-UNED C/Madrid 126, 28903, Getafe, 2014, disponible en: http://hdl. handle.net/10016/18206 [consultado el 14 de septiembre de 2017]. 
Espín Alba, I. (coord). Propiedad intelectual en el siglo XXI: nuevos continentes y su incidencia en el derecho de autor, Madrid, Reus, 2014.

Excepciones de Berna no Sujetas a la Regla de los Tres Pasos, disponible en: http:// keionline.org/node/1518 [consultado el 30 de agosto de 2016].

FInK, C. "La observancia de los derechos de propiedad intelectual desde una perspectiva económica”, OMPI-Comité asesor sobre Observancia, 5. a sesión, Ginebra, 4 de noviembre de 2009.

Glosario de la OMPI de Derecho de Autor y Derechos Conexos, Ginebra, 1980, voz 262, p. 268.

Ortiz Repiso, V. y Moscoso, P. "La biblioteca digital: inventado el futuro", INFO 2002, La Habana, IDICT, 2002.

Pabón Cadavid, J. Guía de derecho de autor para la bibliotecas, Javegraf, disponible en: blogs.ujaen.es/abiertobuja/wp-content/uploads/2014/06/GuiaDerechoAutorBibliotecas.pdf [consultado el 26 de agosto de 2017].

PABÓN CADAVID, J. "Medidas tecnológicas de protección en el Tratado de Libre Comercio con los Estados Unidos de Norteamérica”, Revista de la Propiedad Inmaterial, Universidad Externado de Colombia, n.o 10-11, 2006-2007, pp. 93-115.

Pelaya, L. y Sanllorenti, A. "El acceso a la información en el contexto de la Ley 11.723: una mirada desde las bibliotecas", en ACBJ. Revista de la Asociación Civil de Bibliotecarios Jurídicos, n. ${ }^{\text {4 }}$, Abeledo Perrot, 2009.

Ramírez Céspedes, Z. "Criterios e indicadores para evaluar las bibliotecas digitales", Revistas Acimed, vol. 14, n. ${ }^{\circ}$ 6, noviembre-diciembre 2006, disponible en: http://bvs.sld.cu/revistas/aci/vol14_6_06/aci04606.htm [consultado el 15 de enero de 2016].

URRA P. "Análisis del paradigma de la complejidad para reducir la perplejidad que produce el acceso a las redes”, INFO-2006, La Habana, IDICT, 2006.

Velázquez, A. C. "Declaración Universal de los Derechos Humanos: artículo 27, derecho a la cultura", en La Declaración Universal de los Derechos Humanos en su 50 aniversario, Barcelona, Bosch, 1998.

York V. A. "Biblioteca digital. Recursos y proyectos". Disponible en; http://www. cg.org.br/gt/gtbv/yorkatibict/tsld004.htm [consultado el 30 de septiembre de 2017].

\section{TEXTOS LEGALES}

Acuerdo sobre los Aspectos de los Derechos de Propiedad Intelectual relacionados con el Comercio (15 de abril de 1994), Acuerdo de la Organización Mundial del Comercio, Anexo 1C, Instrumentos Legales - Resultados de la Ronda Uruguay (1994) vol. 31(33) I.L.M. (Acuerdo sobre los ADPIC).

Convenio de Berna para la Protección de Obras Literarias y Artísticas. Publicaciones ompi, No. 223(s), Ginebra, 1999. 
Ley sobre Derecho de Autor cubana, Ley 14 de 28 de diciembre de 1977, Gaceta Oficial, edición ordinaria, La Habana.

Ley Tipo de Túnez de 1976 sobre Derecho de Autor para los Países en Vías de Desarrollo, IGC (1971)/II/II; LA.77/CONF.603/COL.5, UNESCO, disponible en: http://unesdoc.unesco.org/images/0003/000314/031414sb.pdf [consultado en enero de 2018]. 